\title{
Empreendedorismo Social em contexto Public - Descrição Bibliométrica com suporte em 76 anos de Investigações Indexadas na Web of Science
}

\section{Social Entrepreneurship in a Public Context - Bibliometric Description based on 76 years of Research Indexed in the Web of Science}

\author{
Fabiana Pinto de Almeida Bizarria ${ }^{1,2 *}$, Flávia Lorenne Sampaio Barbosa ${ }^{2}$, Danielle Maria \\ Apolonio Rodrigues $^{2}$, Rogeane Moraes Ribeiro ${ }^{1}$
}

\begin{abstract}
RESUMO
A pesquisa objetiva compreender o campo científico do tema Empreendedorismo Social a partir de pesquisas que abordam o campo de públicas. Após levantamento de 157 artigos indexados na base Web of Science, de 1945 a 2021, utilizando-se da palavra "social entrepreneurship", no título, e "public", em todos os campos, os dados foram inseridos no software VOSviewer para a construção dos mapas bibliométricos. Os resultados em relação às redes de (i) co-corrência de palavras-chave, que definiu: cluster 1 agrupou as palavras "field", "innovation", "legitimacy", "organizations", e "performance"; o cluster 2 que reuniu as palavras "challenges", "management", "perspective" e "social innovation"; o cluster 3, uniu as palavras "entrepreneurship", "social economy", "social enterprise" e "social entrepreseurship"; cluster 4 com as palavras "context", "enterprise", "impact" e "work"; cluster 5 "business", "responsibility" e "susteainability". Em relação à rede de (ii) co-citação por artigo, têm-se o cluster 1, com os autores Agafonow (2014), Bacq (2011), Fowler (2000), o cluster 2, com Baron (2007), Hoogendoorn (2016), Short (2009), o cluster 3, com Bacq (2018), Desa (2013) e o cluster 4, representado por Cook (2003), Karosec (2006). Outras três análises evidenciam um campo de estudo atrelado às questões críticas da sociedade, como crises socioambientais.
\end{abstract}

Palavras-chave: Política pública; Empresa social; Desenvolvimento socioambiental;

\section{ABSTRACT}

The research aims to understand the scientific field of the theme Social Entrepreneurship from research that addresses the field of public. After surveying 157 articles indexed in the Web of Science database, from 1945 to 2021, using the word "social entrepreneurship" in the title and "public" in all fields, the data were entered into the VOSviewer software to build the bibliometric maps. The results regarding the networks of (i) co-occurrence of keywords, which defined: cluster 1 grouped the words "field", "innovation", "legitimacy", "organizations", and "performance"; cluster 2 that gathered the words "challenges",

1 Faculdade Luciano Feijão

*E-mail: fabiana.almeida.flf@gmail.com

2 Universidade Federal do Piauí - UFPI 
"management", "perspective" and "social innovation"; cluster 3, joined the words "entrepreneurship", "social economy", "social enterprise" and "social entrepreseurship"; cluster 4 with the words "context", "enterprise", "impact" and "work"; cluster 5 "business", "responsibility" and "susteainability". Regarding the (ii) co-citation network per article, we have cluster 1, with authors Agafonow (2014), Bacq (2011), Fowler (2000), cluster 2, with Baron (2007), Hoogendoorn (2016), Short (2009), cluster 3, with Bacq (2018), Desa (2013) and cluster 4, represented by Cook (2003), Karosec (2006). Three other analyses highlight a field of study tied to critical societal issues, such as socio-environmental crises.

Keywords: Public policy; Social enterprise; Social and environmental development;

\section{INTRODUÇÃO}

O empreendedorismo social tem recebido importante atenção nos últimos anos, sendo um tema ainda considerado recente (CHATTERJEE; CORNELISSEN; WINCENT, 2021; WEVERS; VOINEA; LANGEN, 2020; LAMBRECHTS, CANIËLS; MOLDEREZ; VENN; OORBEEK, 2020; TAUBER, 2021), do início da década de 1990, como exemplo, Waddock e Post (1991); e popularizou na descrição de indivíduos a partir de caraterísticas visionárias, energia e resolutividade em relação aos problemas sociais em suas comunidades (DRAYTON, 2002), também reconhecido como empreendedorismo cívico (KOROSEC; BERMAN, 2006).

Embora muitas pesquisas sobre a definição conceitual (HOOGENDOORN, 2016), que perpassam pela ideia de cooperação (WEVERS; VOINEA; LANGEN, 2020), a desenvoltura e ação colaborativa (RAN; WELLER, 2020; TAUBER, 2021), a personalidade pró-social, a empatia e o compromisso social (LAMBRECHTS et al. 2020), até turismo gastronômico (CELEBI; PIRNAR; ERIS, 2020), e no âmbito do esporte profissional (CHEN; LIN, 2021), o tema recebe questionamentos sobre seu escopo teórico, o que revela necessidade de avaliação crítica de seu panorama, práticase efeitos (DENPSEY; SANDERS, 2010), inclusive para responder questões desafiadoras que surgem, a exemplo da Covid-19 (BACQ; GEOGHEGAN; JOSEFY; STEVENSON; WILLIAMS 2020).

A relevância se faz presente em estudos internacionais a exemplo de pesquisas em regiões de fronteiras da União Europeia (WEVERS; VOINEA; LANGEN, 2020), comparativos entre Polônia e África do Sul (SROKA; MEYER, 2021), em relação ao desenvolvimento da Coreia do Sul (DOH, 2020), em territórios como Jordânia, no Oriente Médio (TAUBER, 2021), em áreas de conflito na Colômbia (CIRUELA-LORENZO; 
GONZÁLEZ-SÁNCHEZ; PLAZA-ANGULO, 2020), em empresas na Espanha (SÁNCHEZ; GUZMÁN; PEÑA-LANG, 2021), com estudantes da China (CHIEN-CHI et al, 2020), caso na Alemanha (CAGARMAN et al, 2020), no contexto italiano (GERLI; CHIODO; BENGO, 2021), na India rural (CHATTERJEE; CORNELISSEN; WINCENT, 2021) e dentre outros.

Ao passo que é considerado um fenômeno paradoxal, por apresentar estruturação advinda dos elementos empresariais e anexar ações da lógica social (WELLER; RAN, 2020; Ran, 2020), considera-se que seu diferencial esteja na produção de bens e serviços de valor social em função de problemas sociais complexos e atender necessidades sociais de maneira sustentável (DENPSEY; SANDERS, 2010; PERRINI; VURRO; COSTANZO, 2010; BECKER; KUNZE; VANCEA, 2017; RAN, 2020; CHATTERJEE; CORNELISSEN; WINCENT, 2021; LAMBRECHTS et al, 2020; TAUBER, 2021; SROKA; MEYER, 2021).

Este diferencial, ainda, imprime fragilidade conceitual ao tema (CHLIOVA; MAIR; VERNIS, 2020; RAN, 2020; CHATTERJEE; CORNELISSEN; WINCENT, 2021), posto a invasão de princípios de mercado, como, por exemplo, eficiência, modelos de negócios baseados em lucro, em detrimento de análises mais voltadas às respostas frente aos problemas sociais coletivos, lógica que impacta valores relacionados à, por exemplo, equidade e justiça (DENPSEY; SANDERS, 2010), com potencial de desenvolvimento de organizações e do seu entorno em formas inovadoras de abordar necessidades socioeconômicas não atendidas (PERRINI; VURRO; COSTANZO, 2010). Dessa forma, reconhece-se a contribuição do empreendedorismo social para o desenvolvimento regional sustentável, com amparo em engajamento comunitário (DOH, 2020; MÉNDEZ-PICAZO; GALINDO-MARTÍN; CASTAÑO-MARTÍNEZ, 2021).

Assim, para avançar no aprofundamento compreensivo sobre empreendedorismo social a partir de pesquisas que abordam o campo de públicas, no caminho de apresentar tendências e diretrizes de pesquisas, objetiva apresentar estudo bibliométrico de artigos indexados na base Web of Science (WoS), ao passo que o estudo dos textos de maior representatividade da bibliometria poderá contribuir com a elucidação de aspectos que fragilizam a abordagem conceitual, agregando as pesquisas futuras aportes teóricos que visam superar desafios relacionados a consolidação do tema. 


\section{PANORAMA TEÓRICO SOBRE EMPREENDEDORISMO SOCIAL}

Desafios à definição do campo teórico do empreendedorismo social também envolvem críticas por associação a agenda neoliberal, ante o reconhecimento de que problemas sociais são de natureza pública e devem ser atendidos pelo Estado (COOK; DODDS; MITCHELL, 2003). Outros autores apontam ambiguidades em relação ao empreendedorismo social, como, por exemplo, Chliova, Mair e Vernis (2020), Ran e Weller (2020), Lambrechts et al. (2020) e Tauber (2021), com argumentos que perpassam a heterogeneidade das empresas desta natureza, bem como a diversidade de maneiras de abordar o empreendimento, que vai desde negócio social (TAUBER, 2021; SROKA; MEYER, 2021; LAMBRECHTS et al. 2020; RAN, 2020; CHLIOVA; MAIR; VERNIS, 2020), empresa/missão social (SROKA; MEYER, 2021; LAMBRECHTS et al. 2020), a concepção de ser caraterística da empresa seu modelo inspirador em prol da mudança de teor social, onde o serviço prestado se sobrepõe à centralidade do lucro, quando a categoria de produto, serviços e os benefícios gerados enfatizam metas sociais bem definidas (SROKA; MEYER, 2021).

O empreendedorismo social trata-se de uma empresa social em modelo híbrido com objetivo econômico, onde o lucro é reinvestido com vistas à realização dos objetivos sociais, gerando impacto social com base em captação de recursos financeiros (CHLIOVA; MAIR; VERNIS, 2020; LAMBRECHTS, 2020; RAN, 2020; CHLIOVA; MAIR; VERNIS, 2020, SROKA; MEYER 2021). Nesse sentido, há referência à finalidade clara da ação empreendedora, no sentido social, cultural e/ou ambiental, em atenção específica às comunidades locais, com base em gestão idealmente democrática (BECKER; KUNZE; VANCEA, 2017), o que, por exemplo, pode-se ser identificado pela relação entre o tema e comunidade local, movimentos e conflitos sociais, ao expressarem normas, valores e ideologias em prol do empreendedorismo social (BECKER; KUNZE; VANCEA, 2017). Tal ênfase pode ser particularmente identificada em estudos na América Latina, em que esse modelo de empreendimento está associado à sociedade civil, em função das condições socioeconômicas de maior fragilidade dos governos e dos setores privados (KERLIN, 2010).

Nesse caminho, para o empreendedorismo social considera-se a necessidade de alinhamento de valores organizacionais e os valores da comunidade para a mobilização do apoio necessário para a efetivação das ações e mudanças sociais (CHATTERJJE; 
CORNELISSEN; WINCENT, 2021), ao passo que a comunidade local expressa suas necessidades e as redes relevam importante capital social, bem como abrigo às problemáticas sociais advindas dos efeitos da globalização, por exemplo (MACLEAN; HARVEY; GORDON, 2013). Assim, são as redes e as parcerias, fatores essenciais ao engajamento social, que favoreceram o empreendedorismo social (SIRINE; ANDADARI; SUHARTI, 2020).

Nesse contexto, os membros da comunidade e as redes sociais estabelecidas, são partes da inovação social que agregaram valor, por meio do empreendedorismo social, quando há autogestão, engajamento e compromisso com os problemas do entorno (MACLEAN; HARVEY; GORDON, 2013). Dessa forma, compreende-se que a inovação social é elemento propulsor da estruturação do empreendedorismo social (GERLI; CHIODO; BENGO, 2021; RAN, 2020; TAUBER, 2021; KIM et al. 2020; CHEN; LIN, 2021).

Por meio da inovação social que se geram mudanças que melhoram a qualidade de vida (MACLEAN; HARVEY, GORDON, 2013). Apontam-se oportunidades, desenvolvimento criativo e da tomada de decisão, em que são essenciais a empatia e a autoeficácia empreendedora sob a lente da justiça social e o modo pelo qual esta se expressa na gestão do marketing e da responsabilidade social da empresa (CHEN; LIN, 2021, LIU; LIANG, 2021). Ao encontro da relevância da inovação, autores defendem a urgência de políticas que favoreçam a capacidade de solução criativa frente aos desafios da sociedade (GERLI; CHIODO; BENGO, 2021), o que requer formação de habilidades consideradas fundamentais para o desenvolvimento desses empreendimentos (SÁNCHEZ; GUZMÁN; PEÑA-LANG, 2021), como, por exemplo, autoeficácia e intenção, empreendedoras (CHIEN-CHI et al, 2020; KIM et al. 2020; LIU; LIANG, 2021), atuando como agente fomentador de oportunidade de trabalho (WEVERS; VOINEA; LANGEN, 2020), com capacidade de reduzir impactos ambientais (SROKA; MEYER, 2021). Tais questões são também complexas ao considerar contexto público e privado, ao passo que autores informam baixo apoio do governo ao empreendedorismo social (DOH, 2020).

Avanços apontam que estudos situados revelam que contextos socioculturais compreendem o tema com maior clareza, como exemplo de pesquisas que comparam ocidente e oriente (TAUBER, 2021); aspectos pessoais, como, por exemplo, personalidade, liderança e motivações (LAMBRECHTS et al, 2020); perpassando pelos 
interpessoais, como inspiração e engajamento (SIRINE; ANDADARI; SUHARTI, 2020; SROKA; MEYER, 2021); organizacionais e ambientais (SÁNCHEZ; GUZMÁN; PEÑALANG, 2021); e, ecossistemas de inovação (GERLI; CHIODO; BENGO, 2021).No entanto, tais caminhos investigativos não aprofundam o que Hoogendoorn (2016) apresenta como teses do empreendedorismo social: o fracasso do governo em atender necessidades sociais; a necessária interdependência/ parceria entre governo e empresas sociais, o que prevê investimento público para estes negócios. Como resultado da pesquisa, o autor evidencia a interdependência como ponto essencial ao desenvolvimento do empreendedorismo social, ao passo que sugere que políticas específicas (ou micropolítica) sejam mais efetivas.

Dois pontos adicionais são relevantes do estudo de Hoogendoorn (2016): não constatação de relação ente níveis de renda e riqueza com número de organizações sociais; evidência de relação entre valores voltados à qualidade de vida, proteção ambiental, em consideração ao bem-estar de todos, e atividades de voluntariado e empreendedorismo social. Em referência à Inglehart (2000), Hoogendoorn (2016) informa que os valores são mais presentes nos jovens, estando estes mais propensos a valorizar metas laborais não materiais, o que se pode reconhecer, inclusive, pela ampliação da educação para o empreendedorismo social, bem como maior difusão sobre problemáticas socioambientais (PACHE; CHOWDHURY, 2012).

Ainda na perspectiva de aprofundamento compreensivo, Bacq e Jansen (2011) apresentam estudo que visa delimitar o empreendedorismo social a partir da ideia de indivíduo, do processo, da organização e do meio ambiente, e, em atenção à Steyaert e Katz (2004), definição do espaço do empreendedorismo, a partir da ideia de espaço discursivo (discursos culturais, ecológicos e cívicos), social (processo social e atores sociais) e geográfico (categorias espaciais, entre nações ou regiões e vizinhança). Espaços que devem ser interpretados a partir de diferentes escolas de pensamento, como a Escola de Inovação Social, que foca no indivíduo visionário; e a Escola de Empreendedorismo Social, que enfatiza o empreendimento e o processo de criação de valor.

Com o panorama apresentado, percebe-se alguns avanços no sentido da compreensão do fenômeno, seja no sentido dos aspectos pessoais e sociorelacionais, que abordam o indivíduo, os grupos e os valores envolvidos; o modelo organizacional e ecossistêmico; a responsabilidade socioambiental; a relação com o governo; e a abordagem que dá luz às leituras sobre empreendedorismo, no caso, a partir do indivíduo 
em iniciativas empreendedoras ou com suporte no processo empreendedor com referência no empreendimento. Com isso, agregar dados bibliométricos e leituras associadas à textos de referência ampliam o panorama e o escopo compreendido do tema.

\section{METODOLOGIA}

Na perspectiva de compreender o campo científico do tema empreendedorismo social a partir de pesquisas que abordam o campo de públicas, e, na sequência, apresentar tendências e diretrizes de pesquisas, optou-se por abordagem de caráter exploratóriodescritivo, por investigar o tema por textos indexados na base Web of Science (WoS).

Em pesquisa realizada no dia 12 de julho de 2021, com o filtro temporal de 1945 a 2021, com a palavra "social entrepreneurship", no título do documento, e com o conectivo "and" associando à palavra "public", podendo esta estar em todos os campos dos textos, obteve-se o resultado de 157 artigos.

Para apresentação descritiva dos dados, arquivos foram extraídos da WoS e importados para o software VOSviewer, sendo este utilizado para construir e visualizar mapas bibliométricos (Van Eck \& Waltman, 2010). Com este, pode-se extrair redes de periódicos, pesquisadores, palavras-chave e publicações, baseados por co-citações, acoplamentos e coautorias gerando um resultado a ser visualizado através dos mapas (WALTMAN; VAN ECK; NOYONS, 2010).Como output do software pode-se obter uma visualização organizada em clusters e delimitada por cores, a partir de indicadores de relacionamento, como: citação, co-citação, co-autoria e acolhamento bibliográfico. Dentre variadas de possibilidades de análise, foram realizadas apreciações sobre (i) cocorrência de palavras-chave; (ii) co-citação por artigo; (iii) acoplamento bibliográfico por artigo; (iv) co-citação por artigo e (v) co-citação por autor.

No software VOSviewer, a palavra "ocorrência" significa o número de vezes que a unidade de análise aparece no documento selecionado. O link corresponde aos nós calculados que representam a força da unidade que está em evidência no nó, baseado na densidade expressa e no grau de correlação, ou seja, é uma conexão entre dois itens. Ostrehgth equivale à força representada pelo item, sendo esta força medida proporcionalmente ao número associado ao link strength, e a espessura do link indica a intensidade da cooperação (VAN ECK; WALTMAN, 2010, 2018). 


\section{APRESENTAÇÃO DOS RESULTADOS}

Dois gráficos extraídos do Web of Science representam o volume de publicações em função do ano (Gráfico 1) e, ainda, a quantidade de citações também por ano (Gráfico 2).

Gráfico 1 - Taxa de citação por ano

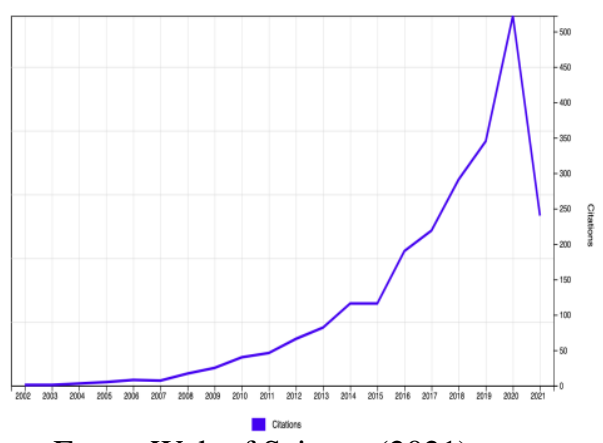

Fonte: Web of Sciense (2021)
Gráfico 2 - Taxa de publicação por ano

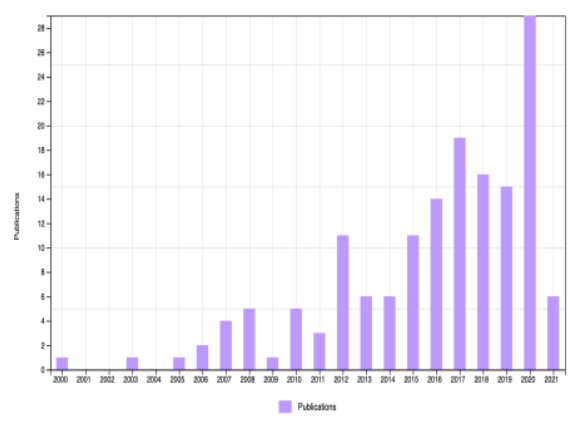

Fonte: Web of Sciense (2021)

Com os Gráficos 1 e 2, observa-se que o ano de 2020 atinge maior volume em número de trabalhos/ artigos publicados e volume de citação, sendo, ainda, expressivo o aumento ao longo dos últimos 5 anos. A Tabela 1 apresenta o conjunto de 15 artigos mais citados dentre os textos selecionados.

Tabela 1 - Referências com maior volume de citações

\begin{tabular}{|c|c|c|c|c|}
\hline $\begin{array}{c}\text { Título } \\
\end{array}$ & Autores & Journal & Ano & Cit* \\
\hline $\begin{array}{l}\text { The multiple faces of social } \\
\text { entrepreneurship: A review of definitional } \\
\text { issues based on geographical and thematic } \\
\text { criteria }\end{array}$ & $\begin{array}{l}\text { Bacq, S.; Janssen, } \\
\text { F. }\end{array}$ & $\begin{array}{l}\text { Entrepreneurshi } \\
\text { p And Regional } \\
\text { Development }\end{array}$ & 2011 & 309 \\
\hline $\begin{array}{l}\text { NGDOs as a moment in history: beyond aid } \\
\text { to social entrepreneurship or civic } \\
\text { innovation? }\end{array}$ & Fowler, A & $\begin{array}{l}\text { Third World } \\
\text { Quarterly }\end{array}$ & 2000 & 193 \\
\hline $\begin{array}{l}\text { Optimization or Bricolage? Overcoming } \\
\text { Resource Constraints in Global Social } \\
\text { Entrepreneurship }\end{array}$ & $\begin{array}{l}\text { Desa, Geoffrey; } \\
\text { Basu, Sandip }\end{array}$ & $\begin{array}{l}\text { Strategic } \\
\text { Entrepreneurshi } \\
\text { p Journal }\end{array}$ & 2013 & 157 \\
\hline $\begin{array}{l}\text { Corporate social responsibility and social } \\
\text { entrepreneurship }\end{array}$ & Baron, David P. & $\begin{array}{l}\text { Journal Of } \\
\text { Economics \& } \\
\text { Management } \\
\text { Strategy }\end{array}$ & 2007 & 144 \\
\hline $\begin{array}{l}\text { The Evolutionary Bases for Sustainable } \\
\text { Behavior: Implications for Marketing, } \\
\text { Policy, and Social Entrepreneurship }\end{array}$ & $\begin{array}{l}\text { Griskevicius, } \\
\text { Vladas; Cantu, } \\
\text { Stephanie M.; van } \\
\text { Vugt, Mark }\end{array}$ & $\begin{array}{l}\text { Journal Of } \\
\text { Public Policy \& } \\
\text { Marketing }\end{array}$ & 2012 & 124 \\
\hline $\begin{array}{l}\text { Meaningful work? Nonprofit marketization } \\
\text { and work/life imbalance in popular } \\
\text { autobiographies of social entrepreneurship }\end{array}$ & $\begin{array}{l}\text { Dempsey, Sarah } \\
\text { E.; Sanders, } \\
\text { Matthew L. }\end{array}$ & Organization & 2010 & 122 \\
\hline $\begin{array}{l}\text { A process-based view of social } \\
\text { entrepreneurship: From opportunity } \\
\text { identification to scaling-up social change in } \\
\text { the case of San Patrignano }\end{array}$ & $\begin{array}{l}\text { Perrini, } \\
\text { Francesco; Vurro, } \\
\text { Clodia; Costanzo, } \\
\text { Laura A. }\end{array}$ & $\begin{array}{l}\text { Entrepreneurshi } \\
\text { p And Regional } \\
\text { Development }\end{array}$ & 2010 & 119 \\
\hline Municipal support for social & Korosec, Ronnie & Public & 2006 & 119 \\
\hline
\end{tabular}




\begin{tabular}{|c|c|c|c|c|}
\hline entrepreneurship & $\begin{array}{l}\text { L.; Berman, Evan } \\
\text { M. }\end{array}$ & $\begin{array}{l}\text { Administration } \\
\text { Review }\end{array}$ & & \\
\hline $\begin{array}{l}\text { Social Entrepreneurs as Institutionally } \\
\text { Embedded Entrepreneurs: Toward a New } \\
\text { Model of Social Entrepreneurship Education }\end{array}$ & $\begin{array}{l}\text { Pache, Anne- } \\
\text { Claire; } \\
\text { Chowdhury, } \\
\text { Imran }\end{array}$ & $\begin{array}{l}\text { Academy Of } \\
\text { Management } \\
\text { Learning \& } \\
\text { Education } \\
\end{array}$ & 2012 & 93 \\
\hline $\begin{array}{l}\text { Institutionalizing social entrepreneurship in } \\
\text { regulatory space: Reporting and disclosure } \\
\text { by community interest companies }\end{array}$ & Nicholls, Alex & $\begin{array}{l}\text { Accounting } \\
\text { Organizations } \\
\text { And Society } \\
\end{array}$ & 2010 & 91 \\
\hline $\begin{array}{l}\text { Social innovation, social entrepreneurship } \\
\text { and the practice of contemporary } \\
\text { entrepreneurial philanthropy }\end{array}$ & $\begin{array}{l}\text { Maclean, Mairi; } \\
\text { Harvey, Charles; } \\
\text { Gordon, Jillian }\end{array}$ & $\begin{array}{l}\text { International } \\
\text { Small Business } \\
\text { Journal }\end{array}$ & 2013 & 73 \\
\hline $\begin{array}{l}\text { Community energy and social } \\
\text { entrepreneurship: Addressing purpose, } \\
\text { organisation and embeddedness of } \\
\text { renewable energy projects }\end{array}$ & $\begin{array}{l}\text { Becker, Soeren; } \\
\text { Kunze, Conrad; } \\
\text { Vancea, Mihaela }\end{array}$ & $\begin{array}{l}\text { Journal Of } \\
\text { Cleaner } \\
\text { Production } \\
\end{array}$ & 2017 & 47 \\
\hline $\begin{array}{l}\text { Social entrepreneurship - False premises and } \\
\text { dangerous forebodings }\end{array}$ & $\begin{array}{l}\text { Cook, B; Dodds, } \\
\text { C; Mitchell, W }\end{array}$ & $\begin{array}{l}\text { Australian } \\
\text { Journal Of } \\
\text { Social Issues } \\
\end{array}$ & 2003 & 47 \\
\hline $\begin{array}{l}\text { Ashoka's big idea: Transforming the world } \\
\text { through social entrepreneurship }\end{array}$ & Sen, Pritha & Futures & 2007 & 46 \\
\hline $\begin{array}{l}\text { The Prevalence and Determinants of Social } \\
\text { Entrepreneurship at the Macro Level }\end{array}$ & $\begin{array}{l}\text { Hoogendoorn, } \\
\text { Brigitte }\end{array}$ & $\begin{array}{l}\text { Journal Of } \\
\text { Small Business } \\
\text { Management }\end{array}$ & 2016 & 42 \\
\hline
\end{tabular}

Fonte: Web of Sciense (2021).

Nota: Volume de citação de 1945 até 12 de julho de 2021.

Em relação a (i) co-corrência de palavras-chave, a Figura 1 apresenta que de 634 palavras-chave presentes na base de dados, 20 atendem ao critério de pelo menos 6 coocorrências, sendo reunidas em 5 clusters, relacionados ao tema de investigação, com 105 links e um total de 263 link strength. 
Figura 1 - Rede de co-ocorrência de palavra-chave

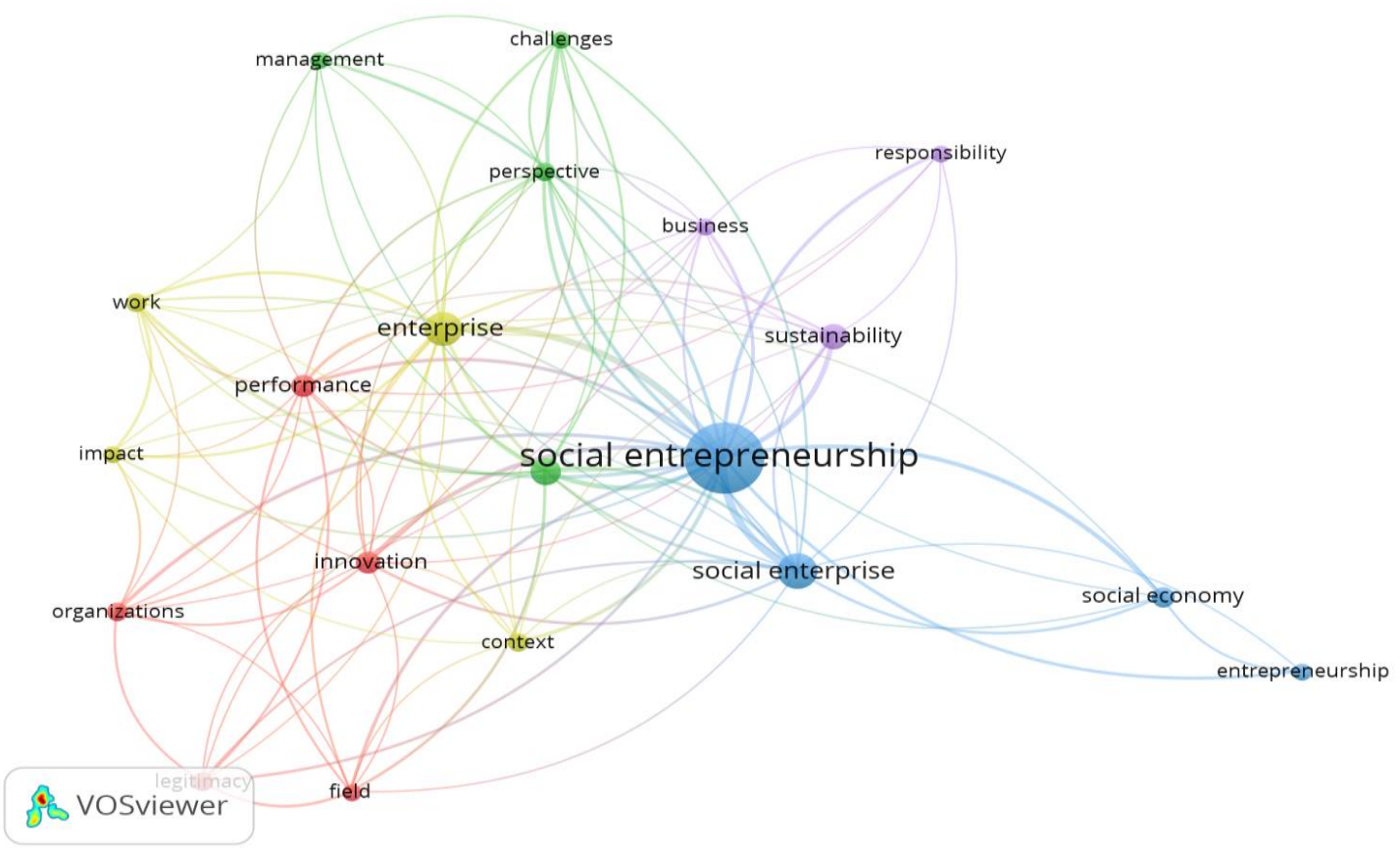

Fonte: Ilustração extraída como output do software VOSviewer (2021).

Com a Figura 1, observa-se a organização de 5 clusters com as palavras-chave. Esses grupos representam a força de ligação da co-ocorrência que, no cluster 1 agrupou as palavras "field" (6 ocorrências, 18 links)", "innovation" (18 ocorrências, 23 links)", "legitimacy" (7 ocorrências, 15 links) "organizations" (7 ocorrências, 17 links) e "performance" (7 ocorrências, 19 links); o cluster 2 que reuniu as palavras "challenges" (6 ocorrências, 19 links), "management" (6 ocorrências, 11 links), "perspective" (7 ocorrências, 19 links) e "social innovation" (15 ocorrências, 30 links); o cluster 3, uniu as palavras "entrepreneurship" (6 ocorrências, 7 links), "social economy" (9 ocorrências, 15 links), "social enterprise" (26 ocorrências, 51 links) e "social entrepreseurship" (101 ocorrências, 123 links); cluster 4 "context" (7 ocorrências, 14 links), "enterprise" (24 ocorrências, 58 links), "impact" (6 ocorrências, 14 links) e "work" (8 ocorrências, 21 links); cluster 5 "business" (6 ocorrências, 16 links), "responsibility" (6 ocorrências, 10 links) e "sustainability" (13 ocorrências, 21 links).

A Figura 2 apresenta a rede de (ii) co-citação por artigo, com base no critério de, no mínimo, 20 citações. Com isso, de 157 artigos, 10 artigos reuniram-se na rede de cocitações, com a formação de 4 clusters e 15 links. 
Figura 2 - Rede de co-citação por artigo

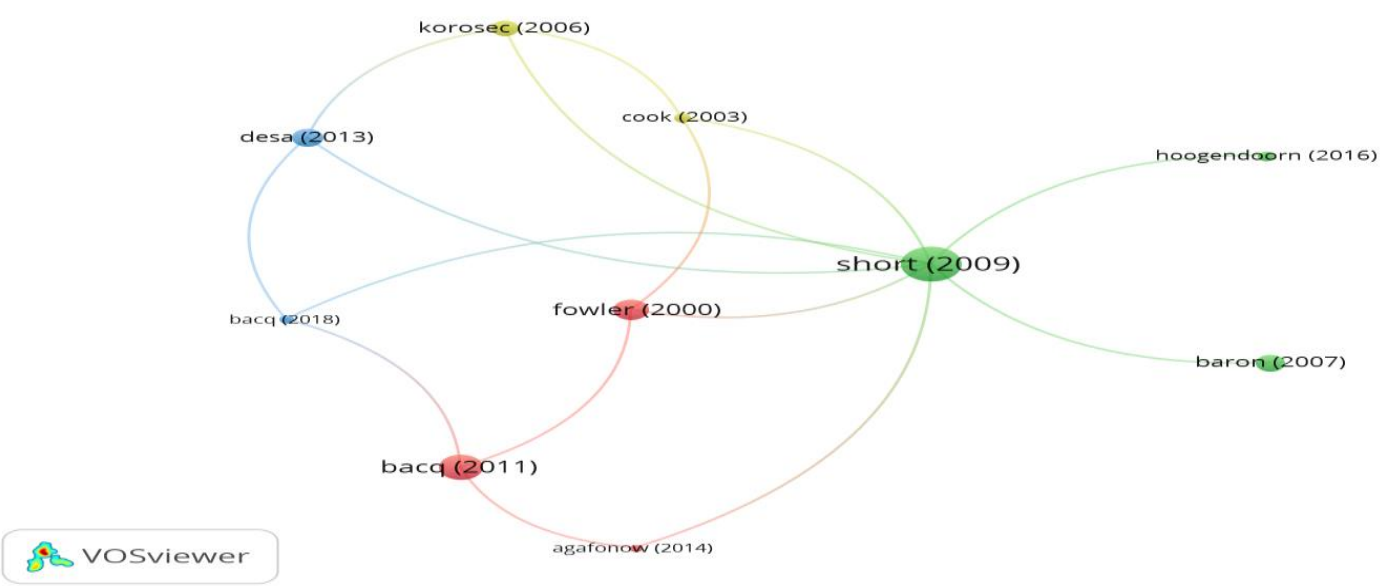

Fonte: Ilustração extraída como output do software VOSviewer (2021)

A Figura 2 apresenta a rede de citações entre textos da base de dados. Como resultado, observa-se 4 agrupamentos, na seguinte organização: cluster 1, reúne os documentos Agafonow (2014), Bacq (2011) e Fowler (2000); o cluster 2, relaciona ostrabalhos de Baron (2007), Hoogendoorn (2016) e Short (2009); o cluster 3, agrupa Bacq (2018) e Desa (2013) e o quarto cluster une Cook (2003) e Karosec (2006).

Na perspectiva do (iii) acoplamento bibliográfico por artigo, dos 157 textos da base de dados, 21 atendem ao critério de, no mínimo 20 citações, que estão representados em 3 clusters, com a presença de 130 links, e um total de 478 links strength.

Figura 3 - Rede de acoplamento bibliográfico por artigo

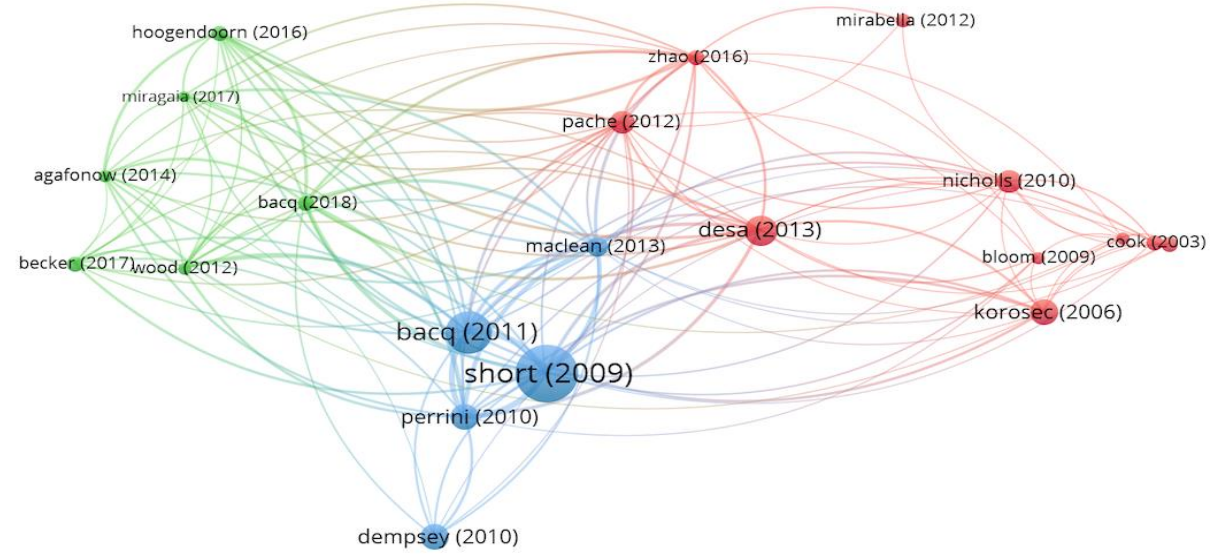

\& \&OSviewer

Fonte: Ilustração extraída como output do software VOSviewer (2021) 
Com base na Figura 3, os 3 clusters, estão representados na sequência: em vermelho, são evidenciadas conexões por uso das mesmas referências entre os artigos de Korosec (2006) (119 citações, 3 links), Desa (2013) (157 citações, 3 links) e Pache (2012) (93 citações, 0 link); em azul conexão entre Short (2009) (574 citações, 8 links), Bacq (2011) (309 citações, 3 links) e Perrini (2010) (119 citações, 1 link); em verde, conexões entre Bacq (2018) (40 citações, 3 links), Agafonow (2014) (31 citações, 2 links) e Hoogendoorn (2016) (31 citações, 1 link).Em relação à Figura 4, com a rede de (iv) cocitação por referência, de 5664 referências citadas, 18 atendem ao mínimo (meet the threshold) de 12 citações. A rede forma 2 clusters, com 148 links e 905 total link strength.

Figura 4 - Rede de Co-citação por referência

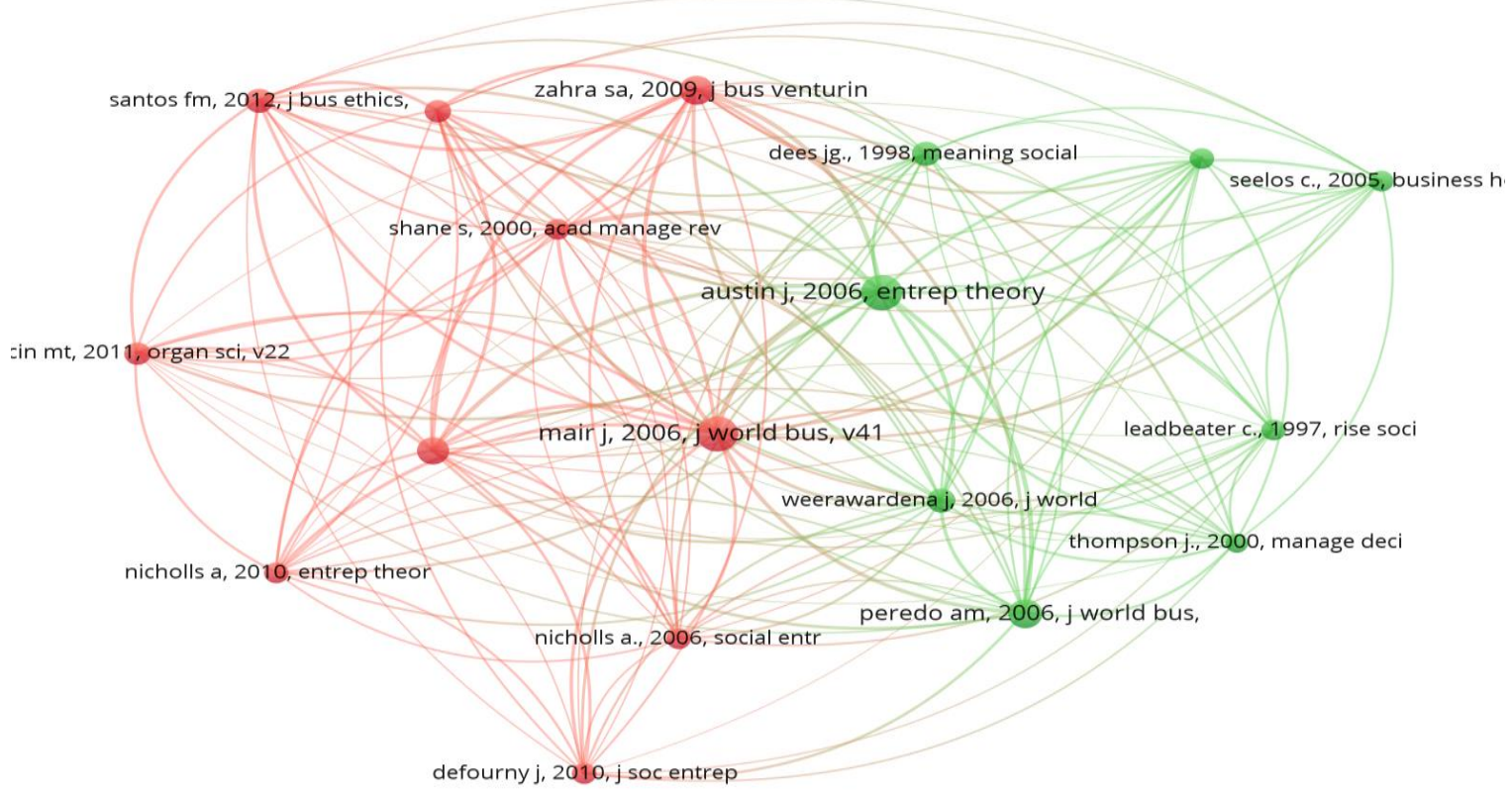

vosviewer

Fonte: Ilustração extraída como output do software VOSviewer(2021)

Em relação à Figura 4, observam-se referências configurados em 2 clusters: em verde, o texto de Austin J. (2006), é o que possui maior representatividade (38 cit., 193 total link strenght), seguido de Peredo A. M. (2006) (28 cit., 119 total link strenght) e, em vermelho, Mair J. (2006) é a principal referência (40 cit., 187 total link strenght), seguido de Zahra S. A. (2006) (27 cit., 150 total link strenght). 
Em relação à Figura 5, com a rede de (v) co-citação por autor, de 4323 autores citados, 18 atendem ao mínimo (meet the threshold) de 20 citações. A rede forma 3 clusters, com 148 links e 905 total link strength.

Figura 5 - Rede de Co-citação por autor

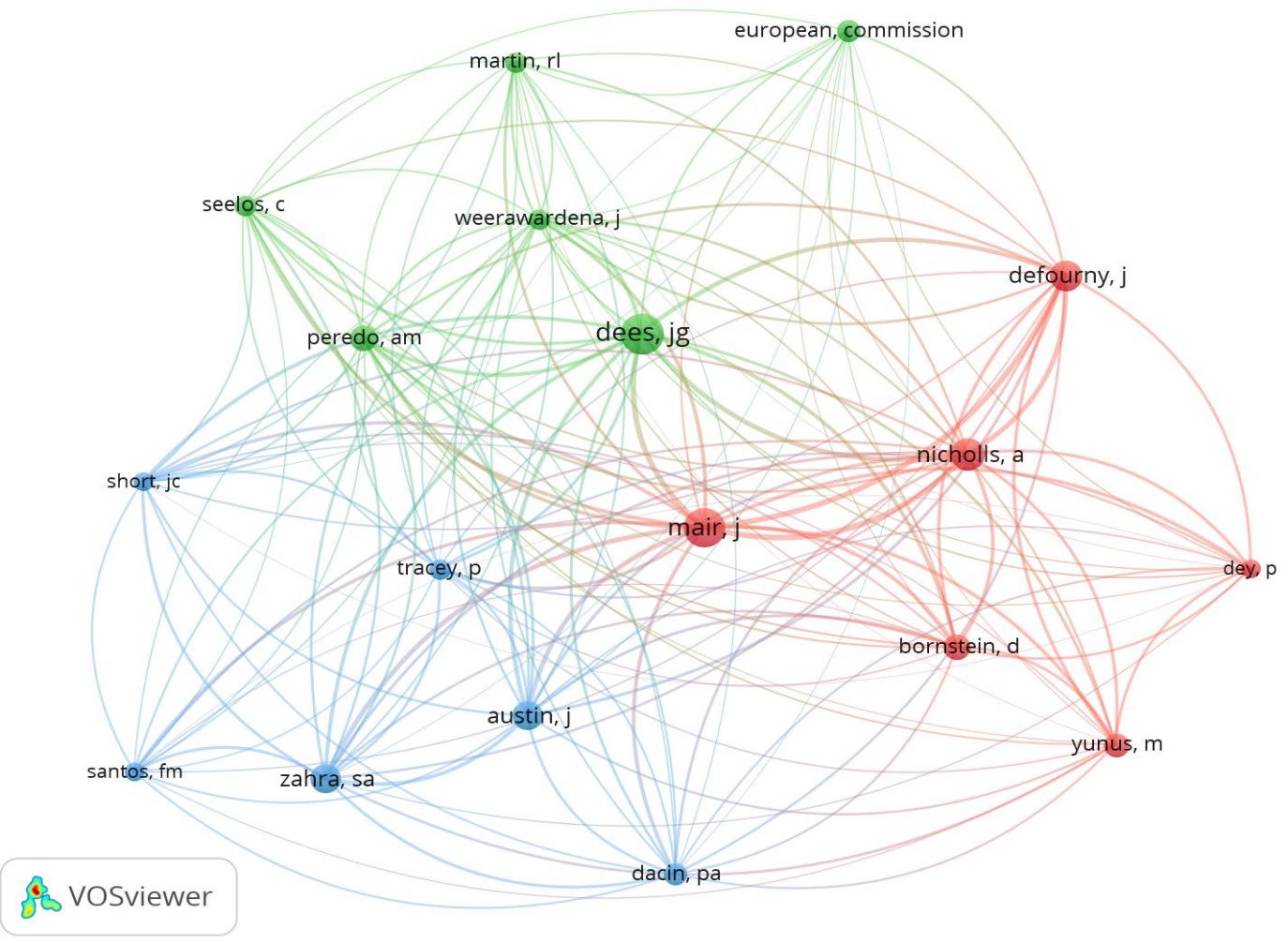

Fonte: Ilustração extraída como output do software VOSviewer (2021)

Em relação à Figura 5, o cluster 1 reúne os autores Mair (80 cit., 689 total link strength), Nicholls, A. (56 cit. 454, total link strength), e Defourny, J. (46 cit., 404 total link strength); o cluster 2, em verde, reúne Dees, J. G. (82 cit., 532 total link strength), Paredo, A. M. (33 cit. 251, total link strength), e Weerawardena, J. (22 cit., 251 total link strength); o cluster 3, em azul, Zahra, S. A. (44 cit. 357, total link strength), Austin, J. (43 cit. 351, total link strength) e Dancin, P. A. (25 cit. 232, total link strength).

Por fim, optou-se analisar os artigos publicados no ano corrente, no caso 2021, para descrever temas recentes de investigação sobre empreendedorismo social (Tabela 2). 
Tabela 2 - Artigos da base publicados no ano de 2021

\begin{tabular}{|c|c|c|c|}
\hline Author Full Names & Article Title & Source Title & Ano \\
\hline $\begin{array}{l}\text { Chandra, Yanto; Lee, Erica } \\
\text { Kim Man; Tjiptono, Fandy }\end{array}$ & $\begin{array}{l}\text { Public versus private interest in social } \\
\text { entrepreneurship: Can one serve two masters? }\end{array}$ & $\begin{array}{l}\text { Journal Of Cleaner } \\
\text { Production }\end{array}$ & 2021 \\
\hline $\begin{array}{l}\text { Lukman, Sadia; Bao, Peng } \\
\text { Xiao; Kweku-Lugu, } \\
\text { Benjamin; Arkorful, } \\
\text { Vincent Ekow; Latif, } \\
\text { Amadu; Gadabu, } \\
\text { Annabelle; Charmaine- } \\
\text { Kwade, Priscilla; Basiru, } \\
\text { Ibrahim; Sadiq, Mohammed } \\
\text { Abubakar }\end{array}$ & $\begin{array}{l}\text { Diasporan students social entrepreneurship } \\
\text { intention: The moderating role of institutional } \\
\text { support }\end{array}$ & Journal Of Public Affairs & 2021 \\
\hline Zhao, Meng & $\begin{array}{l}\text { Social entrepreneurship for systemic change: the } \\
\text { case of Southeast and South Asian countries }\end{array}$ & $\begin{array}{l}\text { Journal Of Asian Public } \\
\text { Policy }\end{array}$ & 2021 \\
\hline $\begin{array}{l}\text { Woods, Christine; Taylor, } \\
\text { Steve }\end{array}$ & $\begin{array}{l}\text { Jesus as a Socially (Ir)responsible Innovator: } \\
\text { Seeking the Common Good in a Dialogue } \\
\text { between Wisdom Christologies and Social } \\
\text { Entrepreneurship }\end{array}$ & $\begin{array}{l}\text { International Journal Of } \\
\text { Public Theology }\end{array}$ & 2021 \\
\hline Chalmers, Dominic & Social Entrepreneurship's Solutionism Problem & $\begin{array}{l}\text { Journal Of Management } \\
\text { Studies }\end{array}$ & 2021 \\
\hline $\begin{array}{l}\text { Kosovych, V; Kosovych, } \\
\text { B.; Rym, O. }\end{array}$ & $\begin{array}{l}\text { Investment Of Social Entrepreneurship In } \\
\text { Ukraine: Current Issues Of Legal Regulation }\end{array}$ & $\begin{array}{l}\text { Financial And Credit } \\
\text { Activity-Problems Of Theory } \\
\text { And Practice }\end{array}$ & 2021 \\
\hline Kovanen, Sunna & $\begin{array}{l}\text { Social entrepreneurship as a collaborative } \\
\text { practice: Literature review and research agenda }\end{array}$ & $\begin{array}{l}\text { Journal Of Entrepreneurship } \\
\text { Management And Innovation }\end{array}$ & 2021 \\
\hline $\begin{array}{l}\text { Ong, Dalphine; Shang, } \\
\text { Liang; Chandra, Yanto; } \\
\text { Hamidi, Mashitah; Wahab, } \\
\text { Haris Abd }\end{array}$ & $\begin{array}{l}\text { The role of social entrepreneurship for youth } \\
\text { purpose development }\end{array}$ & $\begin{array}{l}\text { Journal Of Asian Public } \\
\text { Policy }\end{array}$ & 2021 \\
\hline $\begin{array}{l}\text { Nedospasova, Olga P.; } \\
\text { Pavlova, IrMa A.; } \\
\text { Barysheva, Galina A.; } \\
\text { Rozhdestvenskaia, Elena M. }\end{array}$ & $\begin{array}{l}\text { Formation of Demand for Social } \\
\text { Entrepreneurship to Serve the Interests of the } \\
\text { Older Generation (The Case of Tomsk Oblast) }\end{array}$ & $\begin{array}{l}\text { Tomsk State University } \\
\text { Journal }\end{array}$ & 2021 \\
\hline $\begin{array}{l}\text { Chandra, Yanto; Kerlin, } \\
\text { Janelle A. }\end{array}$ & $\begin{array}{l}\text { Social entrepreneurship in context: pathways for } \\
\text { new contributions in the field }\end{array}$ & $\begin{array}{l}\text { Journal Of Asian Public } \\
\text { Policy }\end{array}$ & 2021 \\
\hline $\begin{array}{l}\text { Chandra, Yanto; Teasdale, } \\
\text { Simon; Tjiptono, Fandy }\end{array}$ & $\begin{array}{l}\text { Social entrepreneurship research in the Greater } \\
\text { China Region: a scoping review and new research } \\
\text { framework }\end{array}$ & $\begin{array}{l}\text { Journal Of Asian Public } \\
\text { Policy }\end{array}$ & 2021 \\
\hline
\end{tabular}

Nota: Dados coletados em 12 de julho de 2021.

Com a Tabela 2, observa-se interesse recente do Jounal of Asian Public Policy em publicações sobre o tema, posto que, de 11 artigos, 4 estão publicados neste periódico. Pelos títulos, observam-se presentes em pesquisas recentes, o dilema público-privado, diáspora, mudança sistémica, religião, regulamentação, prática colaborativa, gerações, e contribuições em forma de framework.

\section{DISCUSSÃO DOS RESULTADOS}

Em relação à tabela 1, observa-se que entre os artigos mais citados da base de dados consta a pesquisa de Bacq e Jansen (2011), com maior volume de citação (309), 
que aborda as múltiplas faces do empreendedorismo social por concepções situadas em duas escolas, a de Inovação Social e a de Empreendedorismo Social. Em forma de contribuição teórica, os autores avançam no levantamento de proposições para o campo, desde a definição de variadas agendas de pesquisas nos EUA e na Europa, o tema percebido como processo visando a criação de valor social, em que há indivíduos visionários que assumem comportamentos empreendedores, até a concepção finalística, onde a missão social sobrepõe o modelo de negócio, podendo este ser híbrido.

Fowler (2000), na sequência, relaciona o empreendedorismo social às Organizações Não Governamentais (ONGs), baseando-se no argumento de ser necessário novos aportes para o funcionamento das ONGs, superando o modelo de doações, face à crescente dependência financeira, para mobilização de redes de empreendedorismo e inovação cívica, com ênfase em princípios da cooperação. Nesse ponto, complementa-se a pesquisa de Desa e Basu (2013), ao reportarem análise sobre a capacidade do empreendedorismo social em mobilizar recursos, desde a visão de dependência de recursos, até a visão baseada em recursos, onde a bricolagem é compreendida como alternativa positiva para empresas sociais.

Baron (2007) associa discussão sobre empreendedorismo social à Responsabilidade Social Corporativa (RSC), ao levantar questionamentos sobre o fato dessas empresas aderirem à RSC para além da maximização do lucro e do valor de mercado. Na visão do autor, em qualquer alternativa de RSC, haverá atendimento do interesse dos acionistas ou empresários em função do contrato social, ao passo que as doações corporativas são substitutos para as doações pessoais, o que para Baron (2007), vai ao encontro do que é defendido por Milton Friedman.

Griskeviscius, Cantú e Vugt (2012), em outro caminho, exploram aspectos relacionados à natureza humana em evolução para compreender o comportamento das pessoas frente aos desafios socioambientais. Compreendem que comportamentos que contribuem para destruição ambiental está associado à evolução do homem em sintonia com problemas sociais modernos. Com isso, definem salutar que formuladores de políticas e empreendedores sociais aproveitem insights sobre as tendências humanas para enfrentar os problemas ambientais e sociais.

Dempsey e Sanders (2010), ainda, analisam o empreendedorismo social sob outra lente, a dos significados atribuídos ao trabalho. A pesquisa ressalta desafios a esse 
significado, ao passo que "fazer o bem”, culturalmente, está atrelado à ideia de penitência, o que leva a um significado moral, o que pode desfavorecer compreensão crítica sobre equilíbrio trabalho e vida, centrado no auto sacrifício, baixa ou ausência de remuneração. São questões basilares à compreensão da dupla lógica dos empreendimentos sociais, no caminho híbrido de seus modelos de negócio, voltados ao social e ao mercado, em configurações que buscam equilíbrio centrado no valor social.

É nesse caminho que Perrini, Vurro e Costanzo (2010) centram sua discussão, ao definir contribuição do empreendedorismo social para o desenvolvimento local e regional, bem como contribuições de Korosec e Berman (2006) no sentido da relevância do envolvimento da gestão dos municípios, com informações, conscientização e formação de líderes comunitários face à capacidade de enfrentamento das problemáticas sociais, coletivas e comunitárias.

Maclean, Harvey e Gordon (2013), ainda, ao conceberem comunidade como espaço de laços, interação e formação de capital social, evidenciam relevância de análises contextuais sobre a dinâmica social onde a inovação se faz presente ante a habilidade em sintonizar demandas, contexto, envolvimento da comunidade e melhoria da vida das pessoas, o que Becker, Kunze e Vancea (2017) definem ser idealmente viável por participação democrática. Tais questões sustentam argumentos de Pache e Chowdhury (2012), sobre a necessidade de investimentos em educação para o empreendedorismo social, tornando estudantes cientes do hibridismo e lógicas presentes nos modelos de negócios sociais, bem como os habilitandos a desenvolver combinações em prol de inovações sociais centradas na contribuição coletiva. O que Sen (2006) define como empreendedores capazes de atuar como catalisadores de transformação social.

Nicolls (2010) colabora com a discussão ao abordar que normativas que regem a regulação dos empreendimentos sociais merecem atenção, face à institucionalização de suas práticas e legitimidade organizacional. Tal suporte normativo, favorável à legitimidade, pode ser caminho de análise sobre críticas lançadas ao empreendedorismo social em função da defesa de sua relação com agenda neoliberal, quando Cook, Dodds \& Mitchell (2003), por exemplo, discutem que a agenda oculta debates sobre causas estruturais relacionados ao desemprego e o papel do Estado em oferecer suporte ao bemestar da população. 
Dentre os textos mais citados, por fim, têm-se o de Hoogendoorn (2016), que colabora com o debate sobre o tema a partir da definição e análise de teses sobre a relação entre sociedade civil, governo e empreendedorismo social. Como resultado, seu estudo compreende necessária maior sintonia entre estes atores, ao passo que a interdependência se apresenta mais favorável ao curso do empreendedorismo social, o que pode ser ativado por políticas públicas de incentivo, bem como atenção aos valores presentes nas iniciativas, posto que preocupação com meio ambiente, qualidade de vida e bem-estar, são valores contributivos às ações pró-sociais.

Em referência aos mapas bibliométricos, têm-se que a rede temática em 5 grupos definem áreas de estudo, como, por exemplo, inovação, legitimidade, organização e desempenho, que podem estar associados às pesquisas sobre a institucionalização e empreendedorismo social (cluster 1); desafios, gestão, perspectiva e inovação social, que se associam às questões gerenciais do empreendedorismo social (cluster 2); empreendedorismo, economia social, empresa social e empreendedorismo social, que se fazem presente em debates sobre a distinção entre o modus operandi do modelo social e o modelo centrado no mercado (cluster 3); contexto, empresa, impacto, trabalho, que estão envolvidas com temas que atravessam a dinâmica da organização, buscando compressão do contexto, do impacto e da dimensão laboral (cluster 4); e, por fim, as palavras negócios, responsabilidade e sustentabilidade, que convergem para discussões sobre a relação do empreendedorismo social centrado em demandas socioambientalmente apresentadas, frente às crises sociais e ambientais.

Observa-se, com a rede (Figura 2), que a co-citação aproxima alguns autores que, possivelmente, atentam-se para definições do fenômeno (cluster 1), visam compreender as bases teóricas e lógicas que estruturam o campo (cluster 2), que buscam contribuir com o modus operandi desde análise do modelo à capitação de recursos (cluster 3), e, ainda, debate sobre a relação Estado, Mercado e Empreendedorismo Social (cluster 4). Destacam-se Fowler (2000) e Bacq (2011) (cluster 1), que também são os artigos de maior volume de citação entre os 157 textos da base, e Short, Moss e Lumpkin (2009) (cluster 2), que apresentam oportunidades de pesquisas para o campo de Empreendedorismo social, a partir da constatação de que há maior volume de pesquisas conceituais, e, além de sugerir esforços empíricos, principalmente, relacionados aos seus determinantes, 
consideram relevante a adesão de teorias como a da contingência, difusão da inovação, dependência, e outras contribuições do ramo do empreendedorismo estratégico.

Em relação ao acoplamento bibliográfico, têm-se que Short, Moss e Lumpkin (2009), apresenta maior volume de citações e de links, seguindo de Bacq e Janssen (2011) e Desa e Basu (2013). A co-citação por referência, por sua vez, tem Austin J. (2006) e de Mair J. (2006) com maior volume de citação e ligação, e a rede de co-citação por autor, apresenta com maior representatividade em função das citações e das ligações, Mair J., Dees, J. G., e Nicholls, A.

Têm-se, portanto, importante contribuição para o campo do empreendedorismo social, como, por exemplo: Johanna Mair, da Escola Hertie de Governança, Alemanha; James Gregory Dees, Duke University; Alex Nicholls, University of Oxford; Geoffrey Desa e Sandip Basu, Department of Management, California, U.S.A.; Sophie Bacq, Indiana University; Frank Janssen, Catholic University of Louvain; James E. Austin, Universidade de Harvard, Jeremy C Short, Universidade do Norte do Texas, Todd W. Moss, Syracuse University; G Tom Lumpkin, University of Oklahoma.

Em análise dos artigos mais recentes, presentes na Tabela 2, observa-se avanço em pesquisas empíricas, a partir do estudo de Chandra, Lee e Tjiptono (2021), Universidade Politécnica de Hong Kong, sobre intenção para iniciar empreendimento social com jovens da geração millennials; Lukman, Bao, Kweku-Lugu, Arkorful, Latif, Gadabu, Charmaine-Kwade, Basiru e Sadiq (2021), da University of Scienceand Technology of China, também sobre a intenção, mas com estudantes em diáspora; Zhao (2021), da Nanyang Technological University, Singapura, com o estudo da mobilização de empreendimentos sociais em prol de mudanças sistêmicas; Woods e Steve (2021), Universidade de Auckland, Nova Zelândia, que estuda a contribuição dos escritos bíblicos para compreender inovação e empreendedorismo social; Chalmers (2021), Universidade de Glasgow, Escócia, que levanta questionamentos sobre a ideia de que empreendedorismo social pode ser a solução para problemas sociais complexos; Kosovych, Kosovych e Rym (2021), Ivan Franko National University of Lviv, que analisam regulamentação legal sobre investimentos em empreendedorismo social; Kovanen (2021), Leibniz Institute for Regional Geography, Alemanha, que por revisão sistemática define agendas de pesquisa voltadas para a relação entre empreendedorismo social e práticas colaborativas; Ong, Shang, Chandra, Hamidi e Wahab (2021), 
Universidade da Malaya, Malásia, contribuem com o estudo sobre o tema a partir da premissa de que o empreendedorismo social pode contribuir com o desenvolvimento do propósito de vida de jovens; Nedospasova, Pavlova, Barysheva e Rozhdestvenskaia (2021), Universidade Estadual de Tomsk, Rússia, estudam a demanda potencial do empreendedorismo social para atender necessidades de idosos; Chandra e Kerlin (2021), Universidade Politécnica de Hong Kong, que, teorizam sobre campo do empreendedorismo social na perspectiva de uma tipologia; Chandra, Teasdale e Tjiptono (2021), que, por meio do estado da arte sobre o tema, em destaque, consideram que os estudos na China seguem o que é estudado pelo ocidente.

Com a busca e apresentação sumária dos autores de maior impacto em análise na base de dados da pesquisa, em associação à compreensão de estudos mais recentes, têmse evidências de que o empreendedorismo social se apresenta como objeto de estudo em variadas partes do mundo, sendo inicialmente estudado, em geral, nos USA, e, mais avançado para países do Oriente, com a percepção de que particularidades devem ser consideradas. Ainda, o avanço das pesquisas, colaboram empiricamente com o tema, em particular, com os determinantes e consequências, principalmente, para os jovens.

\section{CONSIDERAÇÕES FINAIS}

Visando compreender o campo científico do tema empreendedorismo social a partir de pesquisas que abordam o campo de públicas, o estudo apresenta três discussões como considerações finais. Ao assumir a base de dados da Web of Science, de natureza interdisciplinar, os trabalhos levantados, em inglês, privilegiam contribuições escritas por esta língua. Isso demostra, de início, que limitações relacionadas ao presente artigo reporta aos dados presentes na base, compreendendo ser fundamental o mesmo modelo de análise com utilização de outras bases e, ainda, cruzamento dos resultados. Com essa ressalva, pondera-se que tendências e diretrizes de pesquisas devem ser assumidas a partir da base utilizada.

Considerando o lapso temporal de 1945 a 2021, em análise de 157 artigos, observa-se que a contribuição em volume de citações, cocitações, coocorrências, acoplamento bibliográfico privilegiam contribuições teóricas, situadas em países como os Estados Unidos e Alemanha, ao passo que estudos recentes apontam pesquisas de 
natureza empírica em variados países, em especial, a partir do contexto asiático. Com essa constatação, e, ainda, a partir de estudos de Chandra e Kerlin (2021) e Chandra, Teasdale e Tjiptono (2021), observa-se movimento de reconhecimento do contexto regional e local no caminho da teorização sobre empreendedorismo social. Com isso, são definidas como tendência de pesquisa (i) estudos empíricos e regionalizados sobre empreendedorismo social, em análise sobre determinantes e consequentes do fenômeno a partir do contexto sociocultural, institucional e político da região estudada. Contribuições, desta natureza, podem ser oferecidas por pesquisas no campo decolonial, ou pós-colonial, onde o debate sobre racionalidade, ocidente e oriente, Norte e Sul, se fazem presentes.

Também foi evidenciado, em função dos dados bibliométricos que as análises devem percorrer contribuições a partir das concepções definidas e defendidas, da lógica e do equilíbrio entre público-privado na criação de valor social, que envolve a captação e mobilização de recursos. Em associação aos estudos da Tabela 2, tem-se como tendência de pesquisa (ii) análises sobre intenções, atitudes e práticas em empreendedorismo social na configuração do equilíbrio centrado em invocações sociais favoráveis à criação de valor social, face à interdependência entre Estado, empresa e interesses comunitários. Para tanto, aportes teóricos das ciências sociais e da sociologia, da psicologia social e do direito podem agregar contribuições fundamentais para avanços teóricos.

Considerando, ainda, estudos sobre as diferentes gerações, onde a juventude e a velhice se fazem presentes, parece razoável apresentar como tendência de pesquisa (iii) compreensão dos valores e dos motivos relacionados às diferentes gerações frente ao movimento do empreendedorismo social. Adicionalmente, essa tendência também abrange as concepções, representações e significados atribuídos aos negócios sociais.

Ao passo que outras tendências podem ser derivadas dos estudos, aponta-se como diretriz de pesquisa e/ou campo de estudos, a relação entre empreendedorismo social e trabalho, ocupação, ou dimensão laboral, o que a psicologia social do trabalho, em versão crítica, pode melhor fundamentar e configurar desafios e potencialidades em função das subjetividades e subjetivação frente às crises sociais, políticas e ambientais agravadas pela crise do COVID 19, presente desde meados de 2020. 


\section{REFERÊNCIAS}

AGAFONOW. A. Toward a positive Theory of Social Entrepreneurship. On Maximizing Versus Satisficing Value Capture. Journal of Business Ethics. V. 125, n. 4. 2014.

AUSTIN, J.; STEVENSON, H.; WEI-SKILLERN, J. Social and commercial entrepreneurship: same, different, or both?. Entrepreneurship: Theory and Pratice, v. 30, n. 1. P. 1-22. 2006.

BACQ, S; JANSSEN, F. The multiple faces of social entrepreneurship: A review of definitional issues based on geographical and thematic criteria. Entrepreneurship \& Regional Development, v. 23, n. 5-6, p. 373-403. 2011.

BACQ, S.; GEOGHEGAN, W.; JOSEFY, M.; STEVENSON, R.; WILLIAMS, T. A. The COVID-19 Virtual Idea Blitz: Marshaling social entrepreneurship to rapidly respond urgente grand challenges. Business Horizons, p. 1-37. 2020.

BARON, D. P. Corporate Social Responsibility and Social Entrepreneurship. Journal of Economics \& Management Strategy, v. 16, n. 3, p. 683-717. 2007.

BECKER, S.; KUNZE, C.; VANCEA, M. Community energy and social entrepreneurship: Addressing purpose, organisation and embeddedness of renewable energy projects. Journal of Cleaner Production v. 147, p. 25-36. 2017.

CAGARMAN, K.; KRATZER, J.; ARNIM, L. H.; FAJGA, K.; GIESEKE, M. J. Social Entrepreneurship on Its Way to Significance: The Case of Germany. Sustainability, v. 12, p. 1-13. 2020.

CELEBI, D.; PIRNAR, I.; ERIS, E.D. Bibliometric analysis of social entrepreneurship in gastronomy tourism. Review, v. 68, n. 1, p. $58-67.2020$.

CHADRA, Y.; LEE, E. K. M.; TJIPTONO, F. Public versus private interest in social entrepreneurship: Can one serve two masters?. Journal of Cleaner Production , v. 280. P. 1-11. 2021.

CHALMERS, D. Social Entrepreneurship's Solutionism Problem. Journal of Management Studies, v. 58, n. 5. 2021.

CHANDRA, Y.; KERLIN, J. A. Social entrepreneurship in context: pathways for new contributions in the field. Journal of Asian Public Policy, v. 14, n. 2, p. 135-151. 2021

CHANDRA, Y.; TEASDALE, S.; TJIPTONO, F. Social entrepreneurship research in the Greater China Region: a scoping review and new research framework. Journal of Asian Public Policy, 1-30. 2021.

CHATTERJEE, I.; CORNELISSEN, J.; WINCENT, J. Social entrepreneurship and values work: The role of practices in shaping values and negotiating change. Journal of Business Venturing, v. 36, 1-23,[106064]. 2021. 
CHEN, C.-Y.; LIN, Y.-H. Social Entrepreneurship in Professional Sports: Antecedents and Outcomes from the Consumer Perspective. Sustainability, v. 13, n. 1045. 2021.

CHIEN-CHI, C.; SUN, B.; YANG, H.; ZHENG, M.; LI, B. Emotional Competence, Entrepreneurial Self-Efficacy, and Entrepreneurial Intention: A Study Based on China College Students' Social Entrepreneurship Project. Front. Psychol. V. 11, p. 1-13. 2020.

CHLIOVA, M.; JOHANNA M.; VERNIS, A. Persistent Category Ambiguity: The case of social entrepreneurship. Organization Studies, v. 41, n. 7, p. 1019-1042. 2020.

CIRUELA-LORENZO, A.M.; GONZÁLEZ-SÁNCHEZ, A.; PLAZA-ÂNGULO, J. J. An Exploratory Study on Social Entrepreneurship, Empowerment and Peace Process. The Case of Colombian Women Victims of the Armed Conflict. Sustainability, v. 12, 1-26 [10425]. 2020.

COOK, B., DODDS, C.; MITCHELL, W. Social Entrepreneurship- false premises and dangerous forebodings. Australian Jornal Of Social Issues, v. 38, n. 1, p. 57-72. 2003.

DEMPSEY, S.E.; SANDERS, M. L. Meaningful work? Nonprofit marketization and work/ life imbalance in popular autobiographies of social entrepreneurship. Organization, v. 17, n. 4, p. 437-459. 2010.

DESA, G., BASU, S. Optimization or Bricolage? Overcoming resource constraints in global social entrepreneurship. Strategic Entrepreneurship Journal. V. 7, p. 26-49. 2013.

DOH, S. Social Entrepreneurship and Regional Economic Development: The Case of Social Enterprise in South Korea. Sustainability v. 12, p. 1-20. [8843]. doi:10.3390/su12218843. 2020.

DRAYTON, W. The Citizen Sector: Becoming as Competitive and Entrepreneurial as Business. California Management Review, v. 44, 120-133. 2002

FOWLER, A. NGDOS as a moment in history: beyond aid to social entrepreneurship or civic innovation?. Third World Quarterly, v. 21, n. 4, p. 637-654. 2000.

GERLI, F.; CHIODO, V.; BENGO, I. Technology Transfer for Social Entrepreneurship: Designing Problem-Oriented Innovation Ecosystems. Sustainability, v. 13, n. 20. P. 1-19. 2021.

GRISKEVICIUS, V.; CANTÚ, S. M.; VUGT, M. The Evolutionary Bases for Sustainable Behavior: Implications for Marketing, Policy, and Social Entrepreneurship. Journal of Public Policy \& Marketing, v. 31, n. 1, p. 115-128. 2012.

HOOGENDOORN, B. The Prevalence and Determinants of Social Entrepreneurship at the Macro Level. Journal of Small Business Management v. 54, n. S1, p. 278-296. 2016. 
INGLEHART, R. Globalization and Posmodern Values. ReserchGate, v. 23, n. 1. P. 215228. 2000.

KERLIN, J. A. A Comparative Analysis of the Global Emergence of Social Enterprise. Voluntas, v. 21. P. 162-179. 2010.

KIM, M.G.; LEE, J.-H.; ROH, T.; SON, H. Social Entrepreneurship Education as an Innovation Hub for Building an Entrepreneurial Ecosystem: The Case of the KAIST Social Entrepreneurship MBA Program. Sustainability, v. 12, 1-23.[9736]. 2020. doi:10.3390/su12229736.

KOROSEC, R.; BERMAN, E. Municipal Support for Social Entrepreneurship. Technology, Communication, Collaboration. 448-462. 2006.

KOSOVYCH, V; KOSOVYCH, B.; RYM, O. Investment Of Social Entrepreneurship In Ukraine: Current Issues Of Legal Regulation. Financial and Credit activities: Problems of Theory and Practice. V. 37, n. 1. P. 467-475. 2021.

KOVANEN, S. Social entrepreneurship as a collaborative practice: Literature review and research agenda. Journal of Entrepreneurship, Management and Innovation, v. 17, n. 1, 97-128. 2021.

LAMBRECHTS, W.; CANIËLS, M.C.J; MOLDEREZ, I., VENN, R.; OORBEEK, R. Unraveling the Role of Empathy and Critical Life Events as Triggers for Social Entrepreneurship. Front. Psychol. V. 11, p. 1-14.[ 579500]. 2020.

LIU, H.-C.; LIANG, C. How journalism experience translates to social entrepreneurship: An intention formation study of the Art Yard at Dadaocheng in Taiwan. Journal of Entrepreneurship, Management and Innovation, v. 17, n. 1, p. 175-201. 2021.

LUKMAN, S.; BAO, P. X.; KWEKU-LUGU, B.; ARKORFUL, V. E.; LATIF, A.; GADABU, A.; CHARMAINE-KWADE, P.; BASIRU, I.; SADIQ, M. A. Diasporan students social entrepreneurship intention: The moderating role of institutional support. Journal Of public affairs. Wiley, v. 21, p. 1-12. 2021.

MACLEAN, M.; HARVEY, C.; GORDON, J. Social innovation, social entrepreneurship and the practice of contemporary entrepreneurial philanthropy. International Small Business Journal, v. 31, n. 7. P. 747-763. 2013.

MÉNDEZ-PICAZO, M.T.; GALINDO-MARTÍN, M.A.; CASTAÑO-MARTÍNEZ, M.S. Effects of sociocultural and economic factors on social entrepreneurship and sustainable development. Journal of Innovation \& Knowledge, v. 6, p. 69-77. 2021.

NEDOSPASOVA, O. P.; PAVLOVA, I. A.; BARYSHEVA, G. A.; ROZHDESTVENSKAIA, E. M. Formation of Demand for Social Entrepreneurship to Serve the Interests of the Older Generation (The Case of Tomsk Oblast). Tomsk State University Journa, v. 463, 87-97. 2021. 
NICHOLLS, A. Institutionalizing social entrepreneurship in regulatory space: Reporting and disclosure by community interest companies. Accounting, Organizations and Society, v. $35,394-415.2010$.

ONG, D.; SHANG, L.; CHANDRA, Y.; HAMIDI, M.; WAHAB, H. A. The role of social entrepreneurship for youth purpose development. Journal of Asian Public Policy. 1-19. 2021.

PACHE, A-C.; CHOWDHURY, I. Social Entrepreneurs as Institutionally Embedded Entrepreneurs: Toward a New Model of Social Entrepreneurship Education. Academy of Management Learning \& Education, v. 11, n. 3, p. 494-510. 2012.

PERRINE, F.; VURRO, C.; COSTANZO, L. A. A process-based view of social entrepreneurship: From opportunity identification to scaling-up social change in the case of San Patrignano. Entrepreneurship and Regional Development, v. 22, n. 6, p. 515-534. 2010.

RAN, B.; WELLER, S. An Exit Strategy for the Definitional Elusiveness: A ThreeDimensional Framework for Social Entrepreneurship. Sustainability v. 13, p. 1-15. 2021.

SÁNCHEZ, A.V.; GUZMÁN, M.J.A.; PEÑA-LANG, M. B. Um modelo de formación para desarrollar el emprendimiento social. Educar, v. 57, n. 1, p. 97-116. 2021.

SEN, P. Ashoka's big idea: Transforming the world through social entrepreneurship. Futures, 39, 534-553. 2006.

SHORT, J.; MOSS, T. W.; LUMPKIN, G., T. Research in Social Entrepreneurship: past contributions and future opportunities. Journal Strat. Entrepreneurship v. 3, p. 161-194. 2009.

Sirine, H., Andadari, R. K. \& Suharti, L. Social Engagement Network and Corporate Social Entrepreneurship in Sido Muncul Company, Indonesia. Journal of Asian Finance, Economics and Business, v. 11, n. 7, 885-892. 2020.

SROKA, W.; MEYER, N. A Theoretical Analysis Of Social Entrepreneurship: The Case Of Poland And South Africa. Journal Of Eastern European And Central Asian Research, v. 8 , n. 1, p. 114-148. 2021.

STEYAERT, C.; KATZ, J. Reclaiming the space of entrepreneurship in society: Geographical, discursive and social dimensions. Entrepreneurship\& Regional Development, v. 16, n. 3, p. 179-196. 2004.

TAUBER, L. Beyond Homogeneity: Redefining Social Entrepreneurship in Authoritarian Contexts. Journal of Social Entrepreneurship, v. 12, n. 1, p. 50-68. 2021.

VAN ECK, N. J.; WALTMAN, L. Software survey: VOSviewer, a computer program for bibliometric mapping. scientometrics, v. 84, n. 2, p. 523-538. 2010. 
WADDOCK, S. A., post, J. E. Social Entrepreneurs and Catalytic Change. ERIC v. 51, n. 5, p. 393-401. 1991.

WALTMAN, L.; VAN ECK, N.J.; NOYONS, E.C.M. A unified approach to mapping and clustering of bibliometric networks. J. Informetr. V. 4, p. 629-635. 2010.

WELLER, S.; RAN, B. Social Entrepreneurship: The Logic f Paradox. Sustainability, $v$. 12, p. 1-15. [10642]. .2020.

WEVERS, H.T.; VOINEA, C.L.; LANGEN, F. Social Entrepreneurship as a Form of Cross-Border Cooperation: Complementarity in EU Border Regions. Sustainability, v. 12, p. 1-23[ 8463]. 2020.

WOODS, C.; TAYLOOR, Steve. Jesus as a Socially (Ir)responsible Innovator: Seeking the Common Good in a Dialogue between Wisdom Christologies and Social Entrepreneurship. International journal of public theology, v. 15, n. 1, p. 118-142. 2021.

ZHAO, M. Social entrepreneurship for systemic change: the case of Southeast and South Asian countries, Journal of Asian Public Policy. 2020. 